\title{
A Model for the Spacing of Quicklime Pile to Treat High Water Content Loess
}

\author{
Hong Guo $\mathbb{D}^{1,2}$ Yalin Nan $\mathbb{D}^{1},{ }^{2}$ Rui Guo $\mathbb{D}^{1},{ }^{1}$ and Jiangtao Fu $\mathbb{D}^{1}$ \\ ${ }^{1}$ School of Civil Engineering and Architecture, Shaanxi University of Technology, Hanzhong 723001, China \\ ${ }^{2}$ China Electronic Research Institute of Engineering Investigations and Design, Xi'an 710054, China \\ Correspondence should be addressed to Yalin Nan; nan.yalin@dky53.com
}

Received 17 March 2020; Accepted 9 July 2020; Published 31 July 2020

Academic Editor: Giovanni Lancioni

Copyright (c) 2020 Hong Guo et al. This is an open access article distributed under the Creative Commons Attribution License, which permits unrestricted use, distribution, and reproduction in any medium, provided the original work is properly cited.

There has been a long history for foundation treatment by quicklime pile, but as for establishing a more precise model formula used by actual construction, further research is needed to be done at present. Therefore, how to quantitate the factors affecting pile spacing is of great reference value for both actual constructions and theoretical studies. Based on the reference formula for handling weak foundation by lime pile and the practical problems in the western region, mathematical model analysis method is used to get a new model for high water content loess foundation treatment after considering the factors such as pile expanding, construction method, piles arrangement, and calcium oxide content. In this model, pile spacing coefficient is created and the model formula for different construction methods and different pile arrangements is also given. As a result, the reference formula used in high water content loess is somewhat conservative. The new model is also verified to be rational by the actual works at the end of the paper.

\section{Introduction}

Loess, which is an aeolian silt sediment with variable amounts of sand and clay, is often loosely cemented by calcite $\left(\mathrm{CaCO}_{3}\right)$ and widely distributed in Northwest China and other regions in the world. The natural loess, despite its relatively low dry density $\left(1.10-1.68 \mathrm{~g} / \mathrm{cm}^{3}\right)$ and large void ratio usually $(0.67-1.13,[1])$, as shown in Table 1 , can have a relatively stable internal structure due to weak bonding among particles (i.e., metastable). It is well known that loess soils are water-sensitive [2-6]: that is, when water content increases (e.g., after rainfall or irrigation), a loess soil often exhibits a significant decrease in shear strength. For example, the influence of water content on the shear strength of one of the loess soils in Shaanxi Province of China can apparently be seen from reference [1]. High water content loess soils have always been a challenge for geotechnical engineers because such soils often have a very low bearing capacity and their high water content also makes mechanical compaction ineffective. According to previous studies in the literature [7], the friction angle and bearing capacity of loess almost increase linearly with the decrease in water content and void ratio. Although currently there are several methods to treat high water loess soils, for example, CFG pile (cement and fly ash gravel pile) [8] and stone pile [9], these methods tend to be more costly, and more importantly, these piles are not effective in reducing high water content in loess soils. As mentioned above, both water content and dry density have significant effects on the shear strength and the bearing capacity of loess soils, and the key to reinforce loess soils is how to reduce their water content and increase dry density [10]. In this regard, quicklime pile appears a promising solution to treating high water content loess due to its following characteristics: $\mathrm{CaO}$ can absorb water by hydration reaction, during which $\mathrm{CaO}$ itself swells and becomes slaked lime $\left(\mathrm{Ca}(\mathrm{OH})_{2}\right)$ which in turn densifies the adjacent soils and increases their dry density.

Quicklime $(\mathrm{CaO})$ pile is essentially a column filled with compacted or pneumatically densified lime, which has been successfully used in reinforcing soils [11, 12]. Quicklime piles are often installed in either a triangular or rectangular pattern. The spacing [13-17] between lime piles needs to be 
TABLE 1: Cohesion and friction angle in different water content conditions [1].

\begin{tabular}{lccccc}
\hline Water content & $\begin{array}{c}\text { Very } \\
\text { low }\end{array}$ & Low & High & $\begin{array}{c}\text { Very } \\
\text { high }\end{array}$ & Saturated \\
\hline Cohesion $(\mathrm{kPa})$ & $>120$ & $80 \sim 110$ & $40 \sim 80$ & $10 \sim 40$ & $<10$ \\
Friction angle $\left({ }^{\circ}\right)$ & $>33$ & $29 \sim 33$ & $24 \sim 29$ & $23 \sim 24$ & $<23$ \\
\hline
\end{tabular}

properly designed in order to achieve effective yet economic stabilization effect. Two formulas to determine the quicklime pile spacing are reported in the literature, which are a function of the initial and final dry densities of treated soils before and after the quicklime pile treatment and provided in equations (1) and (2) [18].

For a triangular pattern, the center-to-center spacing is given by

$$
S=0.95 D \sqrt{\frac{\rho_{d}^{\prime}}{\rho_{d}^{\prime}-\rho_{d}}},
$$

and for a square pattern, the recommended spacing is as follows:

$$
S=0.89 D \sqrt{\frac{\rho_{d}^{\prime}}{\rho_{d}^{\prime}-\rho_{d}}},
$$

where $\rho_{d}$ and $\rho_{d}^{\prime}$ are the dry densities before and after the quicklime pile treatment, respectively, and $D$ is the quicklime pile diameter.

However, these formulas were developed primarily for soft clay for which quicklime pile has different stabilization mechanisms than those in loess soils, and moreover, these formulas do not consider the following factors: moisture content of loess soils, the quicklime pile's expansion effect, or different installation procedures (i.e., boring and immersing installation methods). Therefore, this paper proposes mathematic models for determining the center-to-center spacing of quicklime piles, which take into account the factors affecting the effectiveness of quicklime piles in stabilizing loess soils. At the end of this paper, a case history where quicklime piles were used to stabilize loess soil in Shaanxi province was analyzed using the formulas proposed herein, and it shows that a good agreement was achieved between the proposed models and the case history project.

\section{Reinforcement Mechanisms of Quicklime Piles}

The mechanisms of soil reinforcement with quicklime piles include three main categories: soil densification due to water content loss and compaction due to swelled quicklime piles, pile strengthening, and composite foundation associated with quicklime pile-soil reactions.

The basis to compute the spacing of quicklime piles is the hypothesis that the amount of water lost in the soil is equal to the amount of water increase in quicklime piles. The water lost from the soil is absorbed by lime pile. In fact, two steps are involved during quicklime hydration process: first, lime and water react to yield hydrated lime, during which 1 unit mass $\mathrm{CaO}$ absorbs 0.32 unit mass water according to the following chemical reaction formula, with the molecular weight of $\mathrm{CaO}$ as the reference:

$$
\mathrm{CaO}+\mathrm{H}_{2} \mathrm{O}=\mathrm{Ca}(\mathrm{OH})_{2}+64.9 \mathrm{~kJ} / \mathrm{mol}
$$

The molecular weight for $\mathrm{Cao}, \mathrm{H}_{2} \mathrm{O}$, and $\mathrm{Ca}(\mathrm{OH})_{2}$ is 56 , 18 , and $74 \mathrm{~g} / \mathrm{mol}$ and their weight ratio is $1,0.32$, and 1.32 , respectively.

Secondly, dry $\mathrm{Ca}(\mathrm{OH})_{2}$ continues to physically absorb water mainly because of the capillary attraction [19] in the $\mathrm{Ca}(\mathrm{OH})_{2}$. This capillary suction will provide a driving force for transferring water from the soil to the pile. This process will reach equilibrium when the dry $\mathrm{Ca}(\mathrm{OH})_{2}$ absorbs a certain amount of water. The previous study indicated that an appreciable amount of water is absorbed during this process [20]. There is an evidence that quicklime pile is neither in the air nor under groundwater in the situation as presented in this paper. However, the average water content of the $\mathrm{Ca}(\mathrm{OH})_{2}(100 \%)$ can be still used when absorbing water in the air. Note that this is under our hypothesis that the quicklime pile can contact to the air in the soil. Hence, 1 unit weight $\mathrm{CaO}$ can absorb 1.64 unit weight water.

The design of the pile spacing is very important. If the pile spacing is too large, water in the soil would not be completely absorbed by the quicklime pile, and, if it is too small, more quicklime piles would be installed which is definitely a waste of time and materials. Hence, the maximum pile spacing is derived herein. It is easy to get the total amount of water one quicklime pile can absorb:

$$
m_{s}=\frac{1}{4} \pi D^{2} \rho_{q} H * 1.64,
$$

where $\rho_{q}$ is the bulk density of quicklime, usually $0.72-1.13 \mathrm{~g} / \mathrm{cm}^{3}, 1.64$ is discussed above, and $H$ is the quicklime pile length.

The total mass of water loss from the affected soil region depends on the quicklime pile arrangement (usually in construction, there are two types of pile arrangements: one is called triangular arrangement (see Figure 1(a)) and the other is square arrangement (see Figure 1(b))). The affected soil regions by quicklime piles are illustrated in Figures 1(a) and 1(b) for triangular and square patterns, respectively.

So for the triangular arrangement and the square arrangement, the total mass of water loss from the affected soil region is presented as follows:

$$
\begin{aligned}
& m_{l}=\frac{\sqrt{3}}{2} \Delta w S^{2} H \rho_{d} \text { (for the triangular arrangement), } \\
& m_{l}=\Delta w S^{2} H \rho_{d} \text { (for the square arrangement), }
\end{aligned}
$$

where $\Delta w$ is the water content change in the soil after the quicklime pile reinforcement and $S$ is the pile spacing.

The water lost from this affected soil region can be completely absorbed by the quicklime piles only if $m_{s} \geq m_{l}$, which yields the upper limit of the center-to-center spacing of quicklime piles. From equations (4)-(6), the following equations can be obtained: 


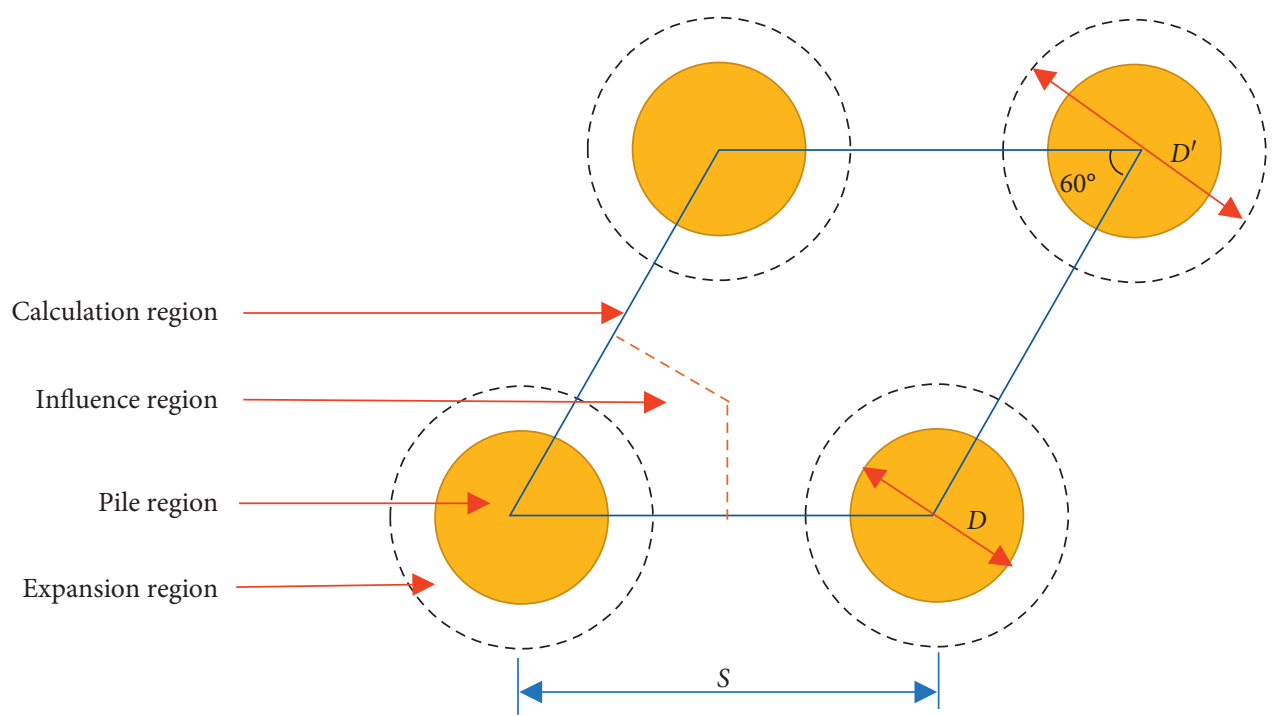

(a)

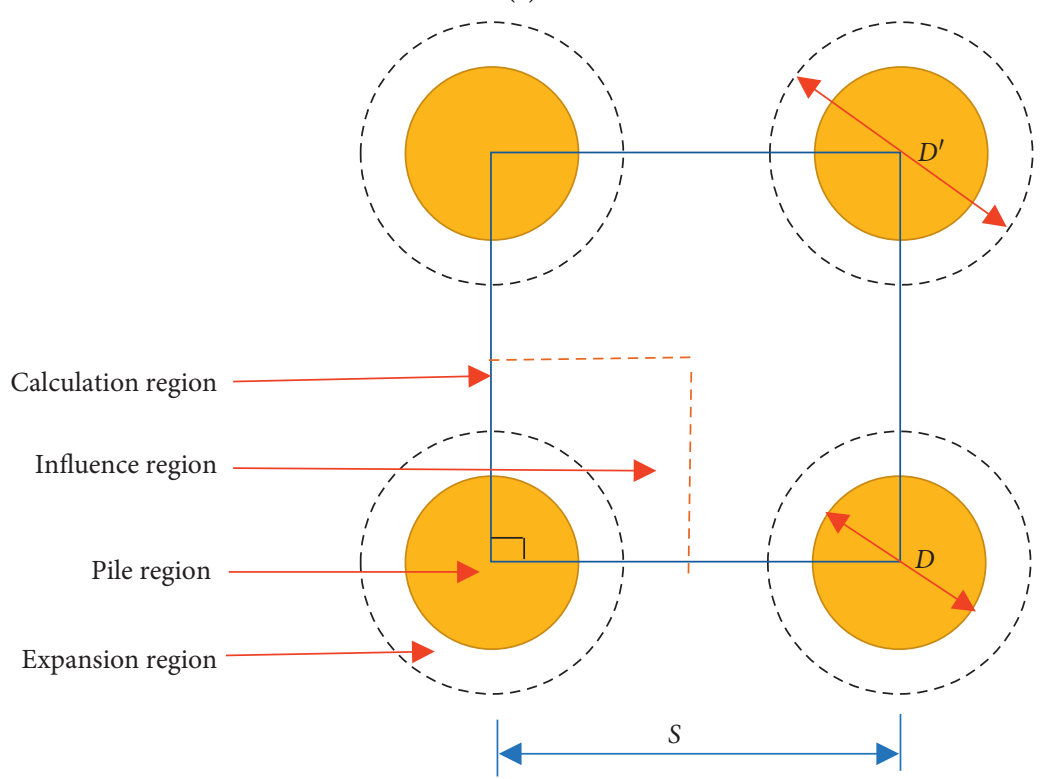

(b)

FIGURE 1: Schematic of quicklime piles installed in a triangular arrangement (a) and a square arrangement (b) and the affected soil range ( $D$ is the initial pile diameter, $D \prime$ is the pile diameter after expansion, and $S$ is the pile spacing).

$S \leq 1.220 \cdot D \sqrt{\frac{\rho_{d}}{\Delta w \rho_{d}}}=L_{s} D$ (for the triangular arrangement),

$$
S \leq 1.135 \cdot D \sqrt{\frac{\rho_{d}}{\Delta w \rho_{d}}}=L_{s} D \text { (for the square arrangement), }
$$

where $L_{s}$ is the maximum quicklime pile spacing coefficient, which is larger than or equal to the designed quicklime pile spacing in order to ensure that the water loss from the reinforced soil is completely absorbed by the adjacent quicklime piles.

The quicklime pile will swell itself after absorbing water. Equations (1) and (2) do not consider this effect, but in this paper, this gap has been covered. After the expansion of the quicklime pile by absorbing water which is lost from the stabilized soil, the volume of a quicklime pile will increase to $k_{v}$ times:

$$
0.25 \pi D^{\prime 2} H=k_{v} 0.25 \pi D^{2} H,
$$

where $D$ is the initial pile diameter, $D \prime$ is the pile diameter after its expansion, and $k_{v}$ is the volume expansion coefficient of quicklime piles. The value range of the expansion coefficient $k_{v}$ is discussed below. Lime pile expansion can be considered, which consists of two parts: one part is due to the absorbed water, which is designated as $k_{v 1}$, and depends on the fraction of the quicklime because sometimes sand or fly ash is added to the quicklime to make the pile together. So $k_{v 1}$ here is 1.65 (quicklime) and 1.33 (ash:lime=3:7), 
respectively, while the other is the expansion associated with pile driving, which is designated as $K_{v 2}$. Because vibration always happens during the pile driving, as a result, the hole in construction would be little bigger than the design value because quicklime lump is filled into the hole that will be hard to exactly control the pile diameter. Gong [21] suggested that the actual pile diameter $D_{0}=[(1.1 \sim 1.2)+$ $30(\mathrm{~mm})] D$. Suppose the pile diameter becomes 1.2 times under driving vibration, in this case $K_{v 2}=1.2^{2}=1.44$. Therefore, the expansion coefficient $k_{v}=k_{v 1} k_{v 2}=$ $1.92 \sim 2.38$.

Also, a quicklime pile itself can support part of the structural loading, especially after the pile is strengthened by the following chemical reaction processes: from $\mathrm{CaO}$ to $\mathrm{Ca}(\mathrm{OH})_{2}$ and then to $\mathrm{CaCO}_{3}$, which has a high strength of $300-500 \mathrm{kPa}$ according to the previous laboratory test [12]. Due to the difference in stiffness between the quicklime pile and the surrounding loess soil, a stress concentration occurs, with a higher stress applied on the quicklime pile than that on the surrounding soil. Thus, the composite quicklime pilesoil forms a stronger foundation. Although ion migration occurring between lime pile and clay soils plays a large role in reinforcing the whole composite foundation, loess soil has limited clay mineral materials and the reinforcement mechanism associated with ion migration of quicklime piles is not relevant and not considered for the case of loess soils.

\section{Mathematical Models for Determining the Center-to-Center Spacing of Quicklime Piles}

Based on the reinforcement mechanisms in loess soils by quicklime piles, mathematic models for determining the center-to-center spacing of quicklime piles are presented in this section, which consider the changes of water content and dry density of the stabilized soil before and after the treatment.

3.1. Center-to-Center Spacing for a Triangular Pattern. As illustrated in Figure 1 for a triangular pattern, one-sixth of a quicklime pile affects one-third of the soil in the triangular area enclosed by quicklime piles. Herein, two triangle regions are taken as the calculation area (Figure 1(a)). As for construction, two installation methods are considered: one method is called boring installation, which involves digging a hole (initial pile diameter) and getting the soil out from the hole and then refilling the hole with quicklime, and the other is called immersing installation method, in which a hollow tube is pushed into the soil to the required depth and quicklime is forced into the tube under pressure as it is withdrawn, and in this case, the soil is still in the ground [10]. So for the first installation method, the total mass of the soil before compaction in our calculation region (that enclosed within the two triangles formed by the adjacent quicklime piles as shown in Figure 1(a)) is calculated as follows:

$$
m=\left(\frac{\sqrt{3}}{2} S^{2}-\frac{\pi}{4} D^{2}\right) H \rho_{d}(1+w)
$$

(for the boring installation method), and for the second installation method, the total mass is given by

$$
m=\frac{\sqrt{3}}{2} S^{2} H \rho_{d}(1+w)
$$

(for the immersing installation method),

where $m$ is the total mass of the soil before compaction; $S$ is the center-to-center pile spacing; $H$ is the quicklime pile length; $\rho_{d}$ is the initial soil dry density; and $w$ is the initial soil water content.

After the soil is stabilized by quicklime piles, the total mass of the soil for both the two installation methods can be calculated from the following equation in which the volume expansion of quicklime piles and the water loss from the stabilized soil are considered:

$$
m^{\prime}=\left(\frac{\sqrt{3}}{2} S^{2}-\frac{\pi}{4} D^{\prime 2}\right) H \rho_{d}^{\prime}\left(1+w^{\prime}\right),
$$

where $m^{\prime}$ is the total mass of the soil after compaction; $\rho_{d}^{\prime}$ is the required soil dry density; and $w^{\prime}$ is the final water content of the stabilized soil.

So from equations (3), (9), (11), and (12), the center-tocenter quicklime pile spacing formula for the boring installation method can be calculated from equation (8), and from equations (4)-(7), the pile spacing formula (14) for the immersing installation method is obtained as follows:

$$
S=0.9523 \sqrt{\frac{\rho_{d}-k_{v} \rho_{d}^{\prime}}{\rho_{d}-\rho_{d}^{\prime}}} D=L_{p} D
$$

(for the boring installation procedure),

$$
S=0.9526 \sqrt{\frac{k_{v} \rho_{d}^{\prime}}{\rho_{d}^{\prime}-\rho_{d}} D}=L_{p} D
$$

(for the immersing installation procedure),

where $L_{p}$ is the quicklime pile spacing coefficient, which is convenient for the design of quicklime piles when their diameter is known. Note that $L_{p}$ should be less than $L_{s}$ during the design process because the water should be completely absorbed by the quicklime pile.

3.2. Center-to-Center Spacing for the Square Pattern. In this case, a pile can reinforce the soil in the square region indicated in Figure 1(b). Based on the similar analysis to that for the triangular layout pattern, the pile spacing formulas are yielded as follows:

$$
S=0.8662 \sqrt{\frac{\rho_{d}-k_{v} \rho_{d}^{\prime}}{\rho_{d}-\rho_{d}^{\prime}} D}
$$

(for the boring installation procedure),

$$
S=0.8662 \sqrt{\frac{k_{v} \rho_{d}^{\prime}}{\rho_{d}^{\prime}-\rho_{d}} D}
$$

(for the immersing installation procedure). 


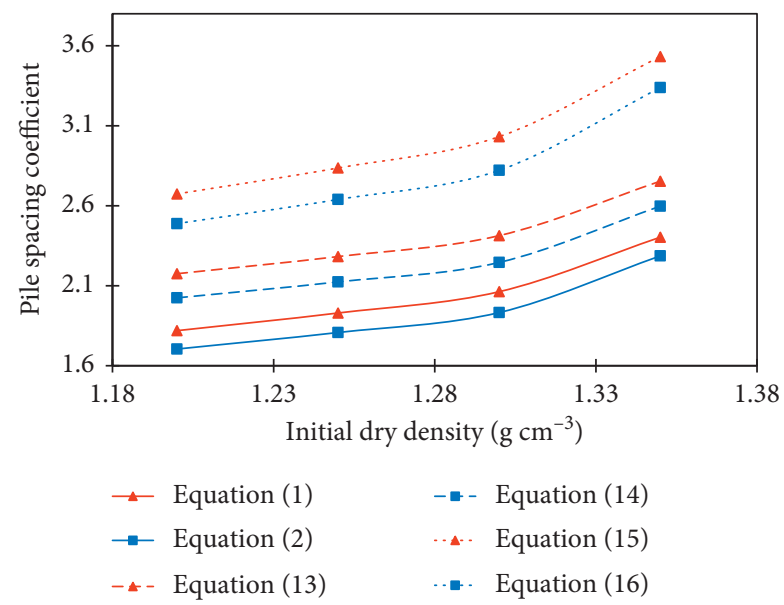

Figure 2: Relation of the initial dry density and pile spacing coefficient $\left(K_{v}=2.15\right)$.

TABLE 2: Physical and mechanical properties of soil.

\begin{tabular}{lcccc}
\hline Soil depth $(\mathrm{m})$ & Water content $w(\%)$ & Dry density $\left(\rho_{d} / \mathrm{g} \cdot \mathrm{cm}^{-3}\right)$ & Void ratio $(e)$ & Specific gravity $(\mathrm{Gs})$ \\
\hline $3.5 \sim 5.5$ & $24 \sim 28$ & 1.31 & 1.06 & 2.70 \\
$5.5 \sim 7.5$ & $22 \sim 24$ & 1.50 & 1.01 & 2.71 \\
\hline
\end{tabular}

\section{Applications and Discussions}

To illustrate the difference in center-to-center spacing of quicklime piles among different spacing formulas, an example is discussed here with the following parameters: an expansion coefficient of 2.15 and the initial dry density ranging from 1.2 to $1.35 \mathrm{~g} / \mathrm{cm}^{3}$, with the calculated spacing plotted in Figure 2 for different formulas and different pile arrangement and different construction methods.

It can be seen from Figure 2 that, in both square and triangular arrangement methods, the pile spacing coefficients in the boring method (equations (8) and (10)) are larger than those in the immersing method (equations (9) and (11)). It also shows that pile spacing coefficient in a triangle pattern is larger than that in a square pattern. That is to say, for the same pile diameter, the number of total piles using the immersing method is less than that using the boring method, and triangular arrangement also makes the total pile number less. This gives us two ideas: first, the former law (equations (1) and (2)) is conservative for loess soil, and second, the immersing construction method is more economical. In addition, when using the immersing method, loess with high water content need not to be drilled out, which is environmentally friendly because high water content loess is very sticky wherever it piled.

Next, the volume of the soil reinforced by the same amount of lime using different layout patterns is calculated as follows: $V=K_{i j} D^{2} H, i=s, z$, and $j=1,2$, where $K_{i j}$ is the volume coefficient, subscript 1 stands for formula (1), 2 for formula (2), $s$ for triangular arrangement, and $z$ for square arrangement. For example, $K_{s 1}$ stands for the reinforced soil volume based on formula (1) using the triangular arrangement.
In order to check the spacing of quicklime piles determined from the proposed formulas (from equations (3) to (6)), a case history in Yangling, Shaanxi, P.R.C., is analyzed using the model this paper presented. Quicklime piles were employed to treat the foundation area of $60 \times 16 \mathrm{~m}^{2}$ of a 6 floor residential building. The building was constructed in 1996, and the quicklime pile-treated foundation performed well since then. The bearing capacities before and after the treatment are 115 and $270 \mathrm{kPa}$, respectively [22].

The groundwater level is about 50 meters below the ground surface, and the physical and mechanical properties of soil are shown in Table 2.

The project above is conducted by the boring method [23], and the piles, with $100 \%$ quicklime, were arranged in a square pattern. And the required dry density of this foundation is $1.65 \mathrm{~g} / \mathrm{cm}^{3}$. From the physical properties summarized in Table 2, and here $k_{v}=2.38$ based on the previous discussion, the pile spacing coefficient is $\left.L_{p}=0.8862 \sqrt{\left(\rho_{d}-k_{v} \rho_{d}^{\prime}\right.} / \rho_{d}-\rho_{d}^{\prime}\right)=2.75 \leq L_{s}$. Note that here $L_{p}=2.75$ should be less than $L_{s}$. So the bulk density of the quicklime should be controlled in the construction process (in the lower right of the black line, $L_{p}<L_{s}$ ). In the actual construction, the pile diameter was $0.18 \mathrm{~m}$, the pile spacing was set to $0.5 \mathrm{~m}$ empirically, and the pile spacing coefficient is $0.5 / 0.18=2.78$, which is pretty similar to the model results proposed here and also indicates that the equations in this paper are reasonable and safe to the construction. If equation (2) is used, the pile spacing would have been $\left.S=0.89 D \sqrt{\left(\rho_{d}^{\prime}\right.} / \rho_{d}^{\prime}-\rho_{d}\right)=0.41 \mathrm{~m}$. This means $19.5 \%$ more quicklime would have been used to reinforce the foundation and longer quicklime installation time. 


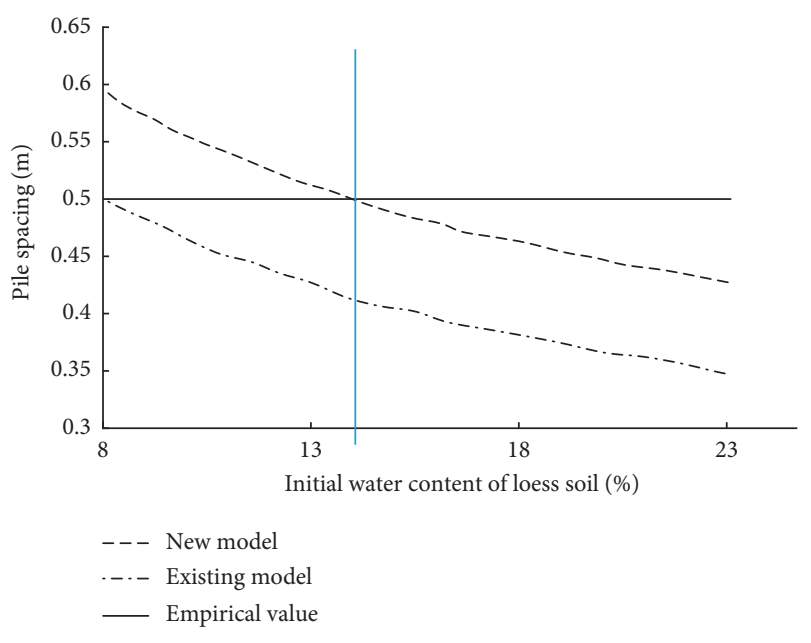

Figure 3: Pile spacing in different models.

The relation of pile spacing and initial water content in empirical value $(0.5 \mathrm{~m})$, existing model (equations (1) and (2)), and the new model presented in this paper is shown in Figure 3. Due to both safe and economical requirements in practical engineering, choosing the suitable pile spacing is of great importance. If the safety requirement is met in one engineering, it is recommended that the bigger pile spacing should be chosen. The empirical value could be chosen for construction when the initial water content of loess soil is equal to or less than $14 \%$. However, when the water content is higher than $14 \%$, if $0.5 \mathrm{~m}$ is still used as the pile spacing, water would not be absorbed completely and also the soil would not reach the required dry density after treatment. The existing model (equations (1) and (2)) seems a more conservative design, and it can meet the dry density requirement but still wastes quicklime and time.

From the discussion about Figure 2, if the triangular arrangement is recommended to this construction, the pile spacing coefficient would be 3.02 and the pile spacing would be $0.54 \mathrm{~m}$; this means $3 \%$ less quicklime would have been used than that in the square arrangement. So it is recommended taking the triangular arrangement as the first option in the design of foundation engineering.

\section{Conclusions}

This paper proposes mathematical models of the center-tocenter spacing of quicklime piles, considering the influence of the following factors: initial water content and dry density of the loess to be treated, the installation patterns of quicklime piles, and the installation methods. The paper also presented a definition of pile spacing coefficient. Some specific conclusions can be drawn: (1) the current formulas are conservative for constructions, but more lime is required; (2) under the same conditions, the triangular arrangement is more economical than the square one; and (3) the immersing installation procedure is more economical than the boring counterpart. Finally, by analyzing the actual engineering and using the model this paper has set, it shows that the formula about the quicklime pile spacing is more economical yet yields satisfactory stabilization effect in high water content loess soils.

\section{Data Availability}

The data used to support the findings of this study are available within the article.

\section{Additional Points}

There has been a long history for foundation treatment by quicklime pile, but as for establishing a more precise model formula used by actual construction, further research is needed to be done at present.

Loess is an aeolian silt sediment with variable amounts of sand and clay and is vulnerable to collapse in case of water immersion. By far, many approaches have been introduced to investigate the roots of loess collapsing. And the results show the microstructure of loess is the main cause leading to its collapsibility. So many methods concerning improving the collapsibility of loess have been proposed based on physical and chemical theory on increasing engineering properties of loess.

This article summarizes recent progress on the cause of loess collapsibility of loess and its improving approaches.

\section{Conflicts of Interest}

The authors declare that they have no conflicts of interest in this work.

\section{Acknowledgments}

The authors would like to express their gratitude to Prof. Mingjiang Tao at WPI (Worcester Polytechnic Institute) for his valuable comments and suggestions during the writing process. This research was funded by Shaanxi Province Key R\&D Program, grant nos. 2020SF-430, 2019ZDLSF05-07, 2018ZDXM-SF-024, and 2017ZDCXL-SF-03-01-01; Scientific Research Plan Projects of Shaanxi Education Department, grant no. 19JK0174; and Research Foundation for Talented Scholars of Shaanxi University of Technology, grant no. SLGQD2017-03.

\section{References}

[1] X. Zuo, H. Lu, and Z. Gu, "Distribution of soil phytolithoccluded carbon in the Chinese Loess plateau and its implications for silica-carbon cycles," Plant and Soil, vol. 374, no. 1-2, pp. 223-232, 2014.

[2] J. Wang, Y. Ma, Q. Guo, and D. Chu, "Influence of pressure and water content on loess collapsibility of the Xixian new area in Shaanxi province, China," Earth Sciences Research Journal, vol. 21, no. 4, pp. 197-202, 2017.

[3] Y. Zhang and M. Weng, "Influence of pile foundation to adjacent tunnel with water immersion in collapsible loess layer of great thickness," Chinese Journal of Rock Mechanics \& Engineering, vol. 36, no. 8, pp. 2040-2050, 2017, in Chinese.

[4] Q. Liang, J. Li, X. Wu, and A. Zhou, "Anisotropy of Q2 loess in the Baijiapo tunnel on the Lanyu railway, China," Bulletin of 
Engineering Geology and the Environment, vol. 75, no. 1, pp. 109-124, 2016.

[5] K. Li, "Analysis and discussion on overburden collapsibility characteristics of loess in an immersion test site," Geotechnical Investigation \& Surveying, vol. 44, no. 4, pp. 34-38, 2016, in Chinese.

[6] P. An, A. J. Zhang, Y. C. Xing, and W.-K. Ni, "Analysis of soak infiltration and deformation characteristics for thick collapsible loess in Ili region," Rock \& Soil Mechanics, vol. 38, no. 2, pp. 557-564, 2017, in Chinese.

[7] H. Xing and L. Liu, "Field tests on influencing factors of negative skin friction for pile foundations in collapsible loess regions," International Journal of Civil Engineering, vol. 16, no. 2, pp. 1413-1422, 2018.

[8] C. Zhang, G. Jiang, X. Liu, and Z. Wang, "Deformation performance of cement-fly ash-gravel pile-supported embankments over silty clay of medium compressibility: a case study," Arabian Journal of Geosciences, vol. 8, no. 7, pp. 4495-4507, 2015.

[9] D. W. Cao, Design and application of broken-stone pile in soft foundation treatment. Nonferrous Metals Design, 2008.

[10] C. D. F. Rogers and S. Glendinning, "Stabilization of shallow slope failures with lime piles," Transportation Research Record: Journal of the Transportation Research Board, vol. 1589, no. 1, pp. 83-91, 1997.

[11] C. D. F. Rogers and S. Glendinning, "Deep-slope stabilization using lime piles," Transportation Research Record, vol. 144, no. 1440, pp. 63-70, 1994.

[12] C. D. F. Rogers and S. Glendinning, "Lime requirement for stabilization," Transportation Research Record: Journal of the Transportation Research Board, vol. 1721, no. 1, pp. 9-18, 2000.

[13] A. T. Ghalesari, A. Barari, P. F. Amini, and L. B. Ibsen, "The settlement behavior of piled raft interaction in undrained soil," in Proceedings of the 2nd International Conference on Geotechnical \& Earthquake Engineering, Chengdu, China, October 2013.

[14] A. T. Ghalesari, A. Barari, P. F. Amini, and L. B. Ibsen, "Development of optimum design from static response of pile-raft interaction," Journal of Marine Science \& Technology, vol. 20, no. 2, pp. 331-343, 2015.

[15] A. T. Ghalesari and A. J. Choobbasti, "Numerical analysis of settlement and bearing behaviour of piled raft in babol clay," European Journal of Environmental and Civil Engineering, vol. 22, no. 8, pp. 978-1003, 2018.

[16] A. T. Ghalesari and H. Rasouli, "The effect of gravel layer on the behavior of piled raft foundations," Advances in Soil Dynamics and Foundation Engineering, ASCE GSP, vol. 240, pp. 373-382, 2014.

[17] M. Modarresi, H. Rasouli, A. T. Ghalesari, and M. H. Baziar, "Experimental and numerical study of pile-to-pile interaction factor in sandy soil," Procedia Engineering, vol. 161, pp. 1030-1036, 2016.

[18] H. X. Gao, Soft Reinforcement, Shanghai Science and Technology Press, Shanghai, China, 1990, in Chinese.

[19] J. A. Cordero, G. Useche, P. C. Prat, A. Ledesma, and J. C. Santamarina, "Soil desiccation cracks as a suctioncontraction process," Géotechnique Letters, vol. 7, no. 4, pp. 279-285, 2017.

[20] Y. Q. He, B. C. Liu, B. P. Jiao, and J. Z. Gan, "Analysis of bearing capacity for quicklime compaction pile composite foundation," Advanced Materials Research, vol. 671-674, pp. 10-13, 2013.
[21] X. N. Gong, Development and Prospect of Ground Treatment, China Water Power Press, Beijing, China, 2004, in Chinese.

[22] H. Guo, Experimental Study on Triaxial Seepage of Disturbed Q3 Loess in Different Regions, Northwest A\&F University, Yangling, Xianyang, China, 2006.

[23] Z. Jia, "The application and analysis of drilling grouting pile construction technology in highway bridge construction," Transportation World, vol. 2017, no. 36, pp. 116-117, 2017, in Chinese. 